\title{
PROGRESS IN PEDIATRICS
}

\author{
DYSENDOCRINISM IN CHILDREN
}

\author{
MARK S. REUBEN, M.D. \\ NEW YORK
}

\section{INTRODUCTION}

In spite of the fact that our knowledge of the internal secretions is rudimentary and confused, great progress has been made during the last ten years in dispelling the uncertainty which surrounds their function both in health and in disease. Everyone must be convinced that these organs are second to none in the body in their influence on physiology, pathology and clinical medicine. Disturbances in the internal secretions are responsible for anomalies of growth and morphogenesis, for disturbed nutrition, disturbed excitability of the nervous system, for loss of resistance to infection and intoxications; they are also responsible for certain dyscrasias and morbid temperaments; and the equilibrium of the nervous system, especially the sympathetic, is also maintained by the internal secretions.

Johannes Müller (1844) and Ruysch showed that the blood received secretions from internal glands. The term "internal secretions" was first used in 1855 by Claude Bernard, who described the glycogenic function of the liver as the "sécrétion interne," while he referred to the preparation of bile as the "sécrétion externe."

It was Berthold of Göttingen who in 1849 first demonstrated by means of experiment, the nature of the activity of a true ductless gland: he showed the influence which can be exerted on the composition of the blood, and thus on the entire organism, by an organ through which the blood stream circulates. He removed the testicles from cocks, and grafted them on another part of the body; he found that the animals remained male in regard to the voice, reproductive instinct, fighting spirit, and growth of comb and wattles.

In 1889, Brown-Séquard, then 72 years of age, described experiments which he had carried out on himself, by the subcutaneous injection of testicular extracts. This really marked the birth of the doctrine of the internal secretions.

The first endocrinous active principle chemically isolated (in 1897) was the hormone of the adrenal medulla, which was given to the world by Abel and Crawford.

The hormone theory originated with Bayliss and Starling in 1902. They discovered that if an extract of the duodenal epithelium is injected into the blood stream a rapid flow of pancreatic juice is 
determined; these observations rendered it clear that this flow of pancreatic juice must be regarded as due to the absorption of some internal secretion into the blood. To the active substance which is yielded by the epithelium cells of the duodenal mucosa they gave the name of "secretin." A similar but not identical internal secretion has been shown by Edkins to be produced by the cells of the mucous membrane of the pyloric end of the stomach. To such stimulating substances as that contained in the extract of the duodenum the term "hormone" ( $\dot{\rho} \rho \dot{a} \omega=$ to stir up) was originally applied by Starling, and the expression has been extended to include the active principles of all internal secretions. Schäfer distinguishes between hormones which promote the activity of another ductless gland and those which have an inhibiting influence. To these latter he applies the term "chalones" ( $\chi a \lambda a$ a $=$ to make slack) and to the former he refers as "hormones." A chalone may therefore be defined as an endocrine product which inhibits or prevents the activity of an organ as distinguished from a hormone, which excites the tissue to increased activity; for both these substances he employs the general term "autacoid substances" (aủtós = self ãkos= remedy).

According to Vincent the process of internal secretion consists in the preparation and setting free of certain substances of physiologic utility (the raw materials for which are supplied by the circulating blood) by certain cells of a glandular type; the substances set free are not passed on to a free surface but into the blood stream. Organs which are not known to possess any other function than that of passing such material into the blood or lymph are termed "internally secreting" or "endocrine" organs ( An endocrine organ may be a special organ (thyroid), a special structure of another organ (pancreas), or it may be neither special structure nor special organ, as the cells which secrete prosecretin, seem to be the ordinary cells which line the mucosa and extend into the glands.

The active materials of the internal secretions are for the most part not rendered inactive by prolonged boiling; they are dialyzable, and act readily on the cells which they influence.

The endocrine organs, although autonomous in their.action, are to some extent influenced by the nervous system, and in turn their autocoids have a tremendous influence on the nervous system; many of the symptoms of dysendocrinism are due to irritation of the nervous system (especially the sympathetic) by abnormal secretions or by normal secretions in an abnormal way (hyposecretion or hypersecretion). The adrenals seem to be most influenced by the nervous system, and the gonads least. Stimulation of a certain spot in the floor of the fourth ventricle, and also at a spot in the regio subthalamica leads to increased secretion of epinephrin. 
Langley divides the vegetative nervous system into two categories, the craniosacral and the sympathetic. In the autonomic nervous system he includes both the craniosacral autonomic nerves (parasympathetic system) and the sympathetic system. Many other writers, however, include only the craniosacral system in the autonomic nervous system and differentiate this system both anatomically and physiologically from the sympathetic system. The action of these two systems of nerves on the different organs which they innervate is antagonistic; for example, the sympathetic nerve accelerates the heart whereas the autonomic vagus nerve slows it.

Modern pharmacology regards as antagonists the sympathetic and the autonomic nervous system. Epinephrin is a specific stimulant of the sympathetic system by its action on the myoneural junction; pilocarpin and muscarin are specific irritants of the autonomic system. Administration of thyroid produces symptoms which simulate those of pilocarpin and muscarin, as, sweating, diarrhea, disturbances in respiration, lymphocytosis, and eosinophilia. Atropin is an antidote for pilocarpin and it also produces symptoms opposite to those of thyroid extract. It has now been attempted, on the basis of these physiologic facts, which indicate that from the thyroid gland impulses may be sent out along the tracts of the sympathetic as well as the autonomic system, to distinguish the symptoms of Graves' disease which might be due to irritation of the sympathetic, from those which might be attributed to autonomic stimulation.

\section{DEVELOPMENT}

It is well known that the adrenals consist of two parts, which; although anatomically united in man, are morphologically distinct and are developed from different embryonic formations. The cortex is formed from mesoderm cells of the genital ridge; the medulla is developed from cells which belong to the same neuroblast masses as give rise to the nerve cells of the sympathetic ganglia. In fishes these parts remain separate, forming "the interrenal bodies," which represent the cortex of the mammal, and the paired chromaffin bodies, which represent the medulla. In all higher vertebrates the two parts are united into one organ; it is only in mammals that the same condition is found as in man, viz., a central medulla with an enclosed cortex.

The infundibulum of the pituitary is composed of nervous tissue and expands in the interior of the gland into the pars nervosa. The anterior lobe is formed by a pouchlike outgrowth of the buccal ectoderm (Rathke's pouch). The posterior lobe is of neuro-ectodermic origin; the pineal gland, like the posterior lobe, is also of neuroectodermic origin. 
The thyroid is found in all vertebrates; it is developed by a median outgrowth from the entoderm lining the floor of the pharynx at a level between the first and the second branchial arches. The parathyroids are developed from outgrowths of the third and the fourth visceral clefts on either side. The thymus is of entodermal origin and arises from the third branchial arch. The pancreas and the mucosa of the small intestine arise from the intestine and are therefore also of entodermal origin.

The gonads arise from the genital ridge, and are therefore, like the adrenal cortex, of mesodermal origin.

It appears that the glands which have a common origin are related in function; thus epinephrin and pituitary extract seem to have the same action; the anterior lobe of the pituitary and the thyroid, both of same origin, are related in function; and finally the adrenal cortex and the gonads, both arising from the mesoderm, are associated in the development of the secondary sex characteristics.

\section{EXPERIMENTAL DATA}

Total removal of the pituitary in adult dogs causes death in two or three days with symptoms of cachexia hypophysipriva. In puppies death does not follow for ten days (3-20). The symptoms of cachexia usually do not appear for from twenty-four to forty-eight hours after the removal of the gland; a marked diminution of urinary output even to antria and a transient glycosuria may occur immediately after operation in adult dogs; and in puppies a postoperative polyuria has been observed, contrasting with the opposite condition seen in adult dogs. The symptoms of cachexia are unsteadiness of gait and lowered body temperature; an awkward arching of the back, with incurvature of the tail is characteristic; later there is still further fall of temperature, slow respiration, slow pulse, irregular muscular contractions, tremors, lethargy, anesthesia, coma and death; the temperature before death may fall 20 degrees C. Grafts in cases of total removal cause a distinct prolongation of life through this means.

The effects of posterior lobe removal are inconclusive; some of the dogs have convulsive attacks with maniacal excitement and persistent erotomania.

The results of partial removal of the anterior lobe are the same if the posterior lobe is removed also. In puppies such removal leads to infantilism. The animals remain undersized and the secondary sexual characteristics do not develop; there is also a tendency to hypotrichosis and to subnormal temperature. In adult dogs partial removal causes adiposity, sexual degeneration, subnormal temperature, hypotrichosis, polyuria and somnolence or restless playfulness. 
Total removal of the anterior lobe causes death in sixty-eight hours with symptoms of cachexia; the consequences of stalk separation are equivalent to total or nearly total hypophysectomy.

They also found that repeated injections of the entire gland cause a rapid loss of weight in puppies and in adult dogs; in cases of anterior lobe insufficiency injections of anterior lobe extract cause a thermic response (from 2 to $4 \mathrm{C}$.).

The occasional appearance of glycosuria after hypophysectomy had led these observers to further study along this line. They noticed that removal of the posterior lobe and part of the anterior lobe causes a primary fall and a subsequent rise above the normal in the assimilation limit for sugars; that removal of part of the anterior lobe, however, produces little or no alteration in the carbohydrate assimilation limit; the removal of posterior lobe alone causes no primary glycosuria, unless there is considerable traumatism of the stalk, but there is an increased sugar tolerance; this increased tolerance can be brought down to normal by giving posterior lobe extract, $1 / 20 \mathrm{gm}$. subcutaneously, $1 / 80 \mathrm{gm}$. intravenously; or $2 / 5 \mathrm{gm}$. by mouth. In man the normal limit for glucose by mouth is $150 \mathrm{gm}$., and for levulose $100 \mathrm{gm}$. It will be seen that in case of posterior lobe insufficiency there is an increased sugar tolerance; such patients can take as much as $400 \mathrm{gm}$. of glucose without appearance of glycosuria.

To summarize, we may say that total removal of the gland, or total removal of the anterior lobe, causes death in two or three days, with symptoms of cachexia. Anterior lobe insufficiency in puppies caused adiposity, skeletal infantilism and failure in appearance of the secondary sexual characteristics; in adult dogs anterior lobe insufficiency causes adiposity and sexual degeneration. The symptoms of posterior lobe insufficiency are increased sugar tolerance, subnormal temperature, hypotrichosis, dry skin, low blood pressure, adiposity and large appetite.

\section{RELATION OF DIABETES INSIPIDUS TO DYSPITUITARISM}

It has long been recognized that polyuria with the appearance of dextrose in the urine is a not infrequent accompaniment of acromegaly; but it is only within the last year that both experimental and clinical evidence has accumulated to prove that diabetes insipidus is probably due to disturbed secretion of the pituitary.

In 1674 Thomas Willis first recognized a distinction between two forms of diabetes, a saccharine and a non-saccharine. Claude Bernard discovered his so-called diabetic center in 1849; this point is situated in the floor of the fourth ventricle, between the centers of the pneumogastric and the auditory nerves; puncture at a point a little lower 
causes simple polyuria, while puncture at a point a little higher in the frontal direction causes albuminuria.

Cushing found that after certain experimental manipulations of the canine hypophysis, a postoperatixe polyuria was of frequent occurrence; in adults oliguria rather than diuresis follows a total extirpation; in younger animals there was diuresis. On the other hand, in a series of partial extirpations, postoperative polyuria was almost always observed. Experiments support the view that the clean-cut posterior lobe removals elicit polyuria with the greatest regularity. Schäfer found that posterior lobe substance given by mouth increases the urinary output; the experimental polyurias have therefore been brought about either by direct hypophysial insult, by the injection of extracts, or by glandular implantations. A hypophysial diuresis may also be elicited by nerve stimulation.

A review of the clinical histories included in many of the past articles on diabetes insipidus makes it clear that a large percentage have shown symptoms found in lesions involving the base of the brain, a gummatous meningitis affecting the structures in the middle cerebral fossa being a particularly common accompaniment of the disorder. Fuchter and Frank have emphasized the surprising frequency with which cases of primary optic atrophy, often with bitemporal hemianopsias which accompany the encephalic polyurias, are classified as diabetes insipidus. Kohler in seven of his twenty-two cases of diabetes insipidus found an affection of the infundibulum; Oppenheim in thirty-six patients with basilar luetic meningitis observed polyuria in twelve; Kruse in thirty-four cases of bitemporal hemianopsia noticed diabetes insipidus in seven cases; Oppenheim in two cases of general cerebral symptoms with double temporal hemianopsia and diabetes insipidus found on necropsy a gumma in the region of the chiasma in one case, and a gummatous meningitis in the region of the chiasma in another; in 1882 Hagenbach found a tubercle in the infundibulum of a girl (4I/2 years old) who had suffered a good deal from thirst and polyuria; in 1903 Rosenhaupt reported a case of diabetes insipidus in which a sarcoma of the anterior lobe of the hypophysis was found; in 1913 Frank reported a case of diabetes insipidus, due to a metastatic carcinoma of the hypophysis, and Simmond reported a case due to a gunshot wound of the hypophysial neighborhood. The evidence, both -experimental and clinical, is therefore in favor of the view that diabetes insipidus is probably a manifestation of dyspituitarism.

\section{EFFECTS OF EPINEPHRECTOMY}

Extirpation of both adrenals is followed by death within from twenty-four to forty-eight hours; careful removal of one adrenal is seldom fatal. If the second adrenal is extirpated some time after the 
first, no effect is at first apparent; later the animal becomes less lively and exhibits signs of muscular weakness; temperature becomes lowered; weakness becomes extreme; the pulse feeble, blood pressure low, and the respiration dyspneic; death soon follows, sometimes immediately preceded by convulsions.

\section{EFFECTS OF THYROIDECTOMY}

Thyroidectomy produces the most marked results in young animals. There is arrest of growth, especially of the skeleton, the cartilage bones long remaining incompletely ossified. Development of the generative organs is much delayed. The integument is swollen, the surface of the skin dry, the hair thin. The muscles are limp and weak; the highest functions of the nervous system remain undeveloped.

\section{EFFECTS OF PARATHYROIDECTOMY}

After complete parathyroidectomy most animals die from within a few days to a few weeks; the most acute symptoms are of a nervous nature. For the first day or two there is only anorexia; later there is exaltation of reflexes, with the occurrence from time to time of fibrillar contractions of muscles, and later cramplike and clonic contractions and eventually convulsive fits; the temperature may rise 2 or 3 degrees $C$. during the fit; there may be attacks of rapid gasping respirations and sometimes vomiting and diarrhea; death may occur within a few days or the affection may last a long time and spontaneous recovery may take place; this symptom complex is known as "tetania parathyreopriva." The parathyroids yield to the blood a special autacoid, of a chalonic nature which tends to prevent overexcitation. In animals which survive parathyroidectomy, changes in the growth and in the structure of the bones and teeth have been noted; in the teeth the calcification appears to be delayed and in the skeleton the bones generally remain smaller than in the controls; thus it is possible that these glands produce a second autacoid which is able to influence calcium metabolism; this is partly substantiated by the finding of an increased excretion of calcium in parathyroidectomized animals.

\section{THYMUS}

Extirpation of the thymus at the height of its development results finally in death; its most important function consists in the inhibition of acids and the consequent removal of injurious substances from the blood; it has a dominating position over the lymphatic apparatus. After thymectomy disturbances occur in calcium metabolism as well as changes in bone and in the central nervous system. 
The results of thymectomy in animals which survive are:

1. The bones were generally distinctly softer and more pliable than in the control animals, and the thymectomized animals were more straddling and awkward in their gait.

2. The thymectomized animals showed less movement and less intelligence.

3. They also showed a distinct backwardness in weight.

4. Galvanic excitability of the peripheral nervous system is distinctly increased after extirpation of the thymus.

\section{PAN CREAS}

In 1889 von Mering and Minkowski proved that the removal of the pancreas or even the greater part of the organ is immediately followed by hyperglycemia leading to a severe and fatal diabetes, whereas this effect is not obtained from mere ligature of the duct. The evidence for the action of an internal secretion which is yielded by the gland and which serves to maintain carbohydrate metabolism in a normal condition is very complete.

\section{THE GONADS}

It was shown by Leydig (1850) that the intertubular connective tissue is characterized by the presence of strands of epithelium-like cells; these have been termed the cells of Leydig, and collectively the interstitial gland of the testes.

If castration is performed in a child the secondary sexual organs remain undeveloped, and other male secondary sexual characters, such as growth of hair on the face and pubes, the enlargement of the larynx, and the development of the male characters of the skeleton, are arrested.

The ovary contains, besides the graafian follicles with their ova, follicular epithelium, and liquor folliculi, a highly vascular stroma formed of a peculiar connective tissue, firm in texture, and containing numerous spindle-shaped cells; these have been named the interstitial cells of the ovary and have been by some thought to be analogous to the interstitial cells of the testicle. The effects resulting from the removal of both ovaries are not so marked externally as in the similar operation in the male sex; if performed in young animals, it is not infrequently found that characters distinctive to the male are to some extent assumed; the uterus remains small; the external changes characteristic of puberty either do not occur or are greatly modified; there is no menstruation; a tendency to the male type of trichosis is often also exhibited.

Experimental evidence seems to point to the fact that the development of corpora lutea leads to the development of the mammae, the 
secretion of milk, and to the hyperplasia of the uterus; its chief function seems to be related to the formation of the uterine decidua and the fixation of the embryo.

\section{PINEAL}

The most complete experiments yet made are those of Foà in the domestic fowl. In pullets in which the gland was destroyed no difference could be noticed on comparison with controls, but in cockerels Foà describes not only a more rapid growth of body but also an earlier development of the testicles and of the secondary sexual characters.

\section{PHYSIOLOGIC ACTION OF ENDOCRINE EXTRACTS PITUITARY EXTRACT}

Extracts of pituitary have a remarkable influence on the vascular system, producing a great rise of blood pressure, with contraction of vessels. The effect on the blood vessels is a direct one; the effect on the heart is different from that of epinephrin, for whereas, with the vagi cut or paralyzed epinephrin causes marked acceleration of heart, pituitary extract causes a slowing of the heart with increased force of individual beats; renal arteries are dilated and there is an increased secretion of urine. This extract powerfully affects the uterus as well as the bladder and the intestine; it also produces dilatation of the pupil of the excised eye of the frog; the secretion of the mammary gland is increased; pituitary extracts cause the disappearance of glycogen from the liver and they facilitate the production of alimentary glycosuria by lowering the limit of assimilation of sugar.

\section{EPINEPHRIN}

Intravenous injection causes an immediate and marked rise of blood pressure, due to contraction of peripheral arteries; concomitant with this is a slowing of the heart's action; there is some diminution in the force of respiration; the arteries of the splanchnic area are the most affected; the cutaneous vessels are strongly contracted; it is always the smaller vessels which are most affected. Other involuntary muscular tissue supplied by sympathetic fibers is also affected, as spleen, vagina, uterus, vas deferens, retractor penis; muscular contraction of intestine, stomach and esophagus is inhibited; muscles of the eye are excited so that the eye tends to protrude and the palpebral fissure appears to enlarge; the third eyelid is retracted and the pupil widely dilated; a flow of saliva is produced; the lacrimal glands are caused to secrete; as a rule there is no increase of sweat secretion.

Locally epinephrin produces marked contraction of the muscular coat. 
THYROID EXTRACTS

Intravenous injections produce (the most common effect) a marked but evanescent fall of blood pressure, dilatation of peripheral vessels and slowing of the heart. Given by mouth thyroid extract reduces blood pressure; large doses produce tachycardia, nervous excitability, flushing of skin, increase of perspiration and increase of nitrogen metabolism. If administration of thyroid is long continued the fat of the body is diminished and glycosuria may be caused; in extreme cases there may be exophthalmos and other symptoms referable to cervical sympathetic excitation, and dilatation of the pupil, psychical excitement, insomnia, tremors, and emaciation. The active substance is iodothyrin or the compound protein iodothyroglobulin. The former was prepared by Baumann (1895) and found by him to contain a marked amount of iodin (0.3-0.9) per mille of dry substance.

\section{EXTRACT OF OTHER ENDOCRINE ORGANS}

Pineal extract, like all other extracts except pituitary and chromaffin, contains depressor substances; later there is a prolonged rise, with dilatation of the kidney volume, and diuresis; there is some increase of contraction of the uterus. Pineal extract is slightly galactogogic.

Mammary extract leads to increased epinephrin in the blood; causes glycosuria, and may arrest development of the embryo, and cause abortion.

Extracts of placenta and fetus produce a chalonic autacoid which have an inhibitory effect on milk secretion.

\section{PARATHYROID EXTRACTS}

Ott found that when parathyroid extracts are given intravenously, the blood pressure is first raised, then lowered; rate of respiration is increased, diuresis is produced, and in large doses they have the effect of lowering the body temperature. Locally extracts have the power to increase the extent of contraction both in intestines and uterus and dilate the pupil.

\section{DYSPITUITARISM}

Vesalius was the first to describe the pituitary, and in his "De Corporis Humani Fabrica" he named it "glans pituitam excipiens"; he believed that this gland secreted the nasal mucus (pituita, phlegm). Galen many years before him knew of this gland, however, and judging from its well protected location thought it was of great importance to the human economy. In 1778, Soemmering described it more fully and called it "hypophysis cerebri." Both Vesalius and Soemmering were of the opinion that the pituitary is a gland; but as they could not 
find any duct, they considered it a part of the nervous system. Wepfer, Bonnet (1679) and Morgagni found colloid cysts in the pituitary, and Greding (1771) and Melcrave observed and described enlargements of the pituitary. Wenzel claimed that diseases of the pituitary may cause epilepsy; in the light of present knowledge this is true, for many patients suffering from dyspituitarism have manifested epileptiform seizures.

In 1838 Rathke discovered the dual origin of this gland from the floor of the third ventricle and from a diverticulum of the pharynx (Rathke's pouch). In 1840, Mohr demonstrated the relation of adiposity to tumors of the hypophysis. In 1860, Liégeois, studying the anatomy of this organ, added it to the list of ductless glands. Marie and Marinesco reported two cases of acromegaly in 1886, and although they were mistaken, in that they thought this disease was due to hyposecretion of this gland, they were the first to draw attention to the relationship between this disease and changes in the hypophysis. About this time Launois described gigantism, and thought that some of these cases may be due to disease of the pituitary; but it was Cunningham who, in 1891, had proved that gigantism and acromegaly are the same disease, the only difference being that gigantism was the result of pituitary disease in cases in which the epiphyseal centers had not yet ossified, and acromegaly in cases in which ossification had taken place. In 1899 Oppenheim recognized the importance of roentgenoscopy of the sellar region as an aid in diagnosis of tumors of the pituitary. Although Pechkranz correlated adiposity with abnormal skeletal changes, with anomalies of the hypophysis, and although Babinski reported a case of tumor of the pituitary without acromegaly in 1900 , Frolich is usually given the credit of describing this type of dyspituitarism, in spite of the fact that his communication did not appear until 1901. To Cushing (1909) is due the credit of putting our knowledge of the secretion of the pituitary on a scientific basis; it is he who pointed out and clearly stated the functions of the individual lobes and showed that clinically we may have many types, depending on whether one or both lobes are hyposecreting or hypersecreting. In 1912 Burnier collected a group of cases in which dwarfism is associated with hypophysial symptoms; he refers to them as cases of "hypophysial nanism."

Sir Victor Horsley was the first to publish a personal note regarding the experimental removal of the gland; the first actual contribution, however, was made by Marinesco (1892); he concluded that the loss of the whole gland was compatible with life for a long time. The first studies which include any suggestive observations on the symptomatology of a pituitarism were published in 1892, and in 1894 by 
Vassale and Sacchi; among others who experimented were Cyon, Caselli, Friedmann, Maas, and von Eiselberg. The most important contribution was made in 1908 by Paulecco of Bucharest; he found that removal of the anterior lobe is equivalent to removal of the entire gland (that is, death in twenty-four hours) ; that loss of the posterior lobe led to no appreciable disturbances, and that separation of the stalk from the base of the brain amounted to a complete or nearly complete removal, as the case might be. In the same year (1908) appeared the notable work of Herring on the anatomy and histology of the pituitary.

The first operations on the hypophysis were by Horsley; the operative procedure in attacking the hypophysis has been studied on cadavers by Lowe and Koening, Jr., but has been cleared essentially by Schloffer, who also operated on the first patient on the Continent in March, 1907.

\section{CLINICAL MANIFESTATIONS OF DYSPITUITARISM}

In man the clinical manifestations are nearly the same as those found by Cushing in dogs; the symptoms resolve themselves into those due to (1) hyposecretion or hypersecretion or perversion of the secretion of the gland itself; (2) those due to increased cerebral pressure; (3) those due to the local pressure of the tumor, and (4) those due to the involvement of the other ductless glands.

Deficiency of anterior lobe in children leads to infantilism; there is inhibition of skeletal development. Hypersecretion of the anterior lobe leads to gigantism in cases in which the epiphyseal centers had not yet ossified, and to acromegaly in adults. That gigantism and acromegaly are closely related is evident from the observations of Sternberg; he found that 20 per cent. acromegalics are over 5 feet 10 inches in height, and that 40 per cent. of all giants have some signs of acromegaly. In hyperpituitarism there is hypertrophic alteration of the skin, and increase in size of the hair follicles; there is also hypertrophy of the papillae and activation of the secretory glands, so that the skin becomes greasy and moist; hypertrichosis is marked. Deficiency of posterior lobe is usually associated with adiposity and increased sugar tolerance; the temperature is usually subnormal, and the subjective chilliness and drowsiness indicate diminished metabolism. The skin is usually smooth-may even suggest edema, but does not pit. The hair on the scalp may be abundant, but axillary and pubic hair may be entirely wanting; the nails are often small and do not show the crescent at their base. Constipation is often obstinate and usually improves on glandular therapy. Psychic disturbances are frequent and are usually due to involvement of frontal and temporal lobes. The symptoms of cerebral involvement are change in disposition, enfeeble- 
ment of memory, disorientation and ". . . notable always is the utter lack of appreciation of, and complete indifference to, the existing condition." In hyperpituitarism, temperamental changes, wakefulness, lack of concentration and irritability are more common; in hypopituitarism mild psychoses to extreme mental derangements with epilepsy are not infrequent. The symptoms of increased cerebral pressure are too well known to need any detailed mention here; they are, in general, headache, general convulsions, double optic neuritis, and optic atrophy, change of position and of mental power, vomiting, vertigo, change in the pulse rate and attacks of syncope.

One of the most important local symptoms is primary optic atrophy; later there is superimposed optic neuritis due to the growth reaching a large state.

Among the most important of the local symptoms is deformation of the sella turcica; extreme hypersecretion and hyposecretion may exist with little if any alteration in the shadow cast by the bony encasement of the gland; the sella may be well preserved, even though the tumor may be enormous and has been of long duration. There are three types of sella deformation; (1) those associated with the thickening of the clinoids and dorsum sellae, (2) those with thinning from pressure absorption of these parts, and (3) those with more or less destruction of all outlines. Equally important are the abnormally small sellae, which accompany the primary glandular hypoplasias of the young.

The following symptoms present in dyspituitarism are referable to secondary involvement of the other ductless. glands: imperfectly acquired secondary sexual characteristics in cases in which the lesion antedates puberty, and of resultant amenorrhea or impotence with retrogressive sexual changes, when the malady develops after the acquirement of adolescence; pigmentation of the skin, asthenia, low blood pressure and hypoglycemia point to adrenal involvement.

\section{CLINICAL TYPES}

One of the earliest types to be recognized is acromegaly. This type is too well known to need any detailed description. Closely associated with this type are the cases of gigantism. Both acromegaly and gigantism are due to hypersecretion of the anterior lobe; gigantism occurs in cases in which the epiphysial centers had not yet ossified, whereas, acromegaly usually occurs in adults; still cases of acromegaly have been reported in children by Antonini and Marzocchi, de Cyon, Rake, Salle and others. The most notable symptoms of acromegaly are skeletel overgrowth, main en large, phalangeal alteration, mandibular prognathism, spacing of teeth, rounding of shoulders, sterno- 
clavicular enlargement, peculiar cranial configuration and hypertrichosis.

Type Fröhlich.-To this type belong those cases which have neighborhood symptoms of tumor of the hypophysis, without any evidences of acromegaly; these cases have a peculiar adiposity, with a feminine type of distribution of the fat when it occurs in males. There is aplasia of the genitals, hypotrichosis, subnormal temperature, undersized stature, psychoses of varying nature and increased carbohydrate tolerance. These cases are due to hyposecretion of the posterior lobe. Such cases in children have been reported by Frölich, Babinski, Hochwart, Uhlthoff, Cagnetto, Erdheim, Israel, Woolcombe, Creutzfeldt, Cushing and others.

Type Burnier.-In 1912 Burnier collected a group of cases from the literature and added one of his own cases, which, in addition to local signs of hypophysial tumor and signs of posterior lobe insufficiency, showed marked dwarfism. These cases are due to hyposecretion of both lobes. The most important symptoms of this type are optic nerve atrophy (almost invariably present), adiposity, dwarfism and atrophy of external and internal genitals. Such cases have been recorded by Burnier, Kon, Benda, Hutchinson, Heuter, Bartels, Nazair, Zöllner, Mixter and Quackenboss and others.

Type Cushing.-It is Cushing who pointed out that a pituitary may be hypersecreting at one time and hyposecreting at another, and that in fact all cases of hyperpituitarism show evidences of hypopituitarism as the disease progresses. It is he also who made the observation that one lobe may be hypersecreting and the other lobe hyposecreting at the same time; and thus we may have a variety of mixed types. He especially called attention to a case of skeletal overgrowth associated with adiposity and sexual infantilism without acromegaly.

\section{DIAGNOSIS}

Diagnosis of acromegaly and gigantism is simple; the Roentgen rays, however, are of great aid. They may show an enlarged sella turcica, or they may show enlargement, broadening and tufting of the phalanges. In posterior lobe insufficiency, the estimation of the sugar tolerance is of importance. We must always suspect posterior lobe insufficiency in individuals who can take more than $150 \mathrm{gm}$. glucose and $100 \mathrm{gm}$. levulose by mouth without glycosuria. In some cases of anterior lobe hyposecretion there is a thermic response when they receive an injection of anterior lobe extract. The symptom-complex of skeletal overgrowth or dwarfism, adiposity, genital atrophy, optic nerve atrophy, deformation of sella and increased carbohydrate tolerance are absolutely pathognomonic of dyspituitarism. 


\section{DISTURBANCES OF THE ADRENALS}

The first definite account of the adrenals is given by Eustachius in 1563. In 1849 Addison observed that certain cases of disease, characterized by pigmentation of the skin, languor, and other symptoms, are associated with destruction, usually tuberculous, of the adrenal bodies. It was Trousseau who first called the condition Addison's disease. In 1894 Oliver and Schäfer discovered the blood pressure raising activity of extracts of the medullary portion of the gland. In 1901 Blum discovered that glycosuria is produced in certain animals following hypodermic injections of epinephrin. In $1897 \mathrm{Abel}$ and Crawford isolated in crystalline form the active principle of the medulla of the gland. Epinephrin and iodothyroglobulin are the only definite internal secretions which have yet been isolated. The adrenal gland is built up of two entirely different tissues. Its medulla is composed of semifluid cells; these cells secrete epinephrin and when heavily loaded with this substance they take a yellow brown stain with chromate salts from which they have acquired the name of chromaffin cells. The cortex forms in man at least 90 per cent. of the entire bulk of the gland. In an encephalic fetus, the cortex is very deficient. The cortical cells seem to be concerned in supplying some secretion which influences the growth and reproductive powers of the animal; these cells are of greater vital importance than the medullary cells.

Diabetic puncture is ineffectual in animals from which the adrenals have been removed; further, in such animals the glycosuria resulting from the extirpation of the pancreas is much reduced. After prolonged use of epinephrin there is marked hypertrophy of the islets of Langerhans as well as of the adrenal bodies. As pointed out by Schäfer, there seem to be connecting links between the glycosuria set up by pancreatic removal and that due to the action of the epinephrin. After extirpation of the adrenals glycosuria cannot be produced by central puncture or by removal of pancreas. Zuelzer found that extirpation of the pancreas carried out at the same time as ligature of the adrenal veins provokes little or no glycosuria. Loewi reports that in diabetes arising after extirpation of the pancreas, epinephrin produces dilatation of the pupil if applied to the conjunctiva, whereas it has no influence on the normal eye. To summarize, it may be said that the function of the medullary portion is to sustain the cardiovascular tone and to produce an antitoxic substance capable of neutralizing toxic products of muscular activity and other undetermined poisons. There are three views as to the function of the cortex: Some believe that it has to do with the growth and development especially of the reproduc- 
tive organs; others, that its main function is the neutralizing of toxic substances, and still others that it has to do with the internal secretion of the medulla. Falta believes that the cortex is a trophic center for beard growth and for the growth of hair on the body.

\section{CLINICAL TYPES}

\section{Hypo-Adrenia}

Addison's Disease.-The symptoms of this disease are too well known to need any detailed mention here. Reference to the physiologic action of epinephrin will explain many of the symptoms which occur in this disease as, hypothermia, coldness, asthenia, hypotension, emaciation, and tendency to syncope. Bronzing is due to an accumulation of melanin in the epidermal layers of the skin, and Sajous believes that the constituent of the oxidizing substance which becomes oxidized when melanin is formed is the adrenal secretion.

Functional Hypo-Adrenia.-Patients suffering from deficiency of adrenal secretion complain of asthenia and are very sensitive to cold; their extremities are always cold and they present the following symptoms: weak cardiac action, and pulse, anorexia, anemia, slow metabolism, constipation and psychasthenia. Children with deficient adrenal secretion are pale and emaciated; they have cold hands and feet and flabby muscles; their appetite is capricious and the blood pressure is low.

\section{Hyperadrenia}

Tumors of Cortex.-In hyperadrenia due to tumors of the cortex, there is an accelerated development of the body and a premature development of the genitals; the infantile type of skeleton, however, is preserved. In some cases there is adiposity; in girls there is premature onset of menstruation and development of the breasts; the hair on the mons veneris, in axilla and on the genitals develops early. Out of seventeen cases collected by Glynn fourteen were in girls. The especial feature of these cases is the early excessive development of the secondary sexual characters and the external genitals; many of these cases present adiposity; associated with the excessive and premature development of body and muscles there is premature ossification and dentition; the mental development of these patients usually corresponds with their age and not with their physical development; the sexual desires are overdeveloped but not to the same degree as are the genitals.

In older children, the symptoms of hypernephroma also manifest themselves by overdevelopment of the sexual sphere. In older girls, menstruation ceases, there is atrophy of the uterus, hypertrichosis of 
masculine type (beard and mustache), hair begins to grow on the whole body, and universal adiposity develops.

It is of interest to note here that in many cases of pseudohermaphroditism of the feminine type, there is found a bilateral hypertrophy of the adrenal cortex.

The enlargement of the adrenal cortex, during breeding, during pregnancy, after castration, and the small size in deficient sexual development are additional evidence of the association of the cortex with sex characters.

DISTURBANCES OF THE THYROID AND THE PARATHYROID

In $1873 \mathrm{Sir}$ William Gull gave the first account of myxedema under the name of "a cretinoid state supervening in adult life in women." Sporadic cretinism was described before this by Hilton Flagg. In 1877 Ord proposed the name myxedema. The symptoms which follow total thyroidectomy were described by J. L. Reverdin in 1882 . In 1883 Kocher called this symptom complex "cachexia strumipriva." The foundations of our present method of treatment have been laid by Schiff, who had shown that successful transplantation of a thyroid gland in a dog sufficed to prevent the development of the symptoms which usually followed its removal. In 1890 Horsley suggested that grafting should be tried as a means of arresting the progress of myxedema. In 1891 Murray was first to suggest the internal administration of the gland (hypodermically); in 1892 MacKenzie and Fox showed that the extract was equally active when given by mouth.

The parathyroids were first described by Sandström in 1880 . In 1891 Gley rediscovered them. The modern theory of the supreme importance of the parathyroids was first clearly put forward by Gley, and has since been elaborated by Vassale and Generali and others.

There are three directions in which the evidence of a functional relationship between the thyroid and the parathyroid glands may be regarded as conclusive:

1. There is the favorable influence of thyroid treatment in the tetania parathyreopriva of animals.

2. We have certain proof of hypertrophy of the external parathyroids, after extirpation of the thyroid gland.

3. There is hypertrophy of the thyroid which follows removal of parathyroids.

In India tetany is a disease of child-bearing women and there is a marked family tendency to the disease. The children of women who suffer from tetany are frequently cretinous. Idiopathic tetany was first described in 1830 by Stringheim. 


\section{CLINICAL TYPES}

\section{Hypothyroidism}

There are three well-recognized types of hypothyroidism: myxedema adultorum, sporadic cretinism, and cretinoid degeneration, which includes simple goiter, goiter heart, endemic cretinism, and endemic deafmutism. The symptoms of these various types are too well known to need repetition here. Differentiation of endemic from sporadic cretinism may be of interest, as cases of the former type may be puzzling and misleading unless one thinks of them. The effect of thyroid therapy is not so constant as in sporadic cretinism; the real myxedematous symptoms are wanting in many cases or are very slight; the manifestations of endemic cretinism are far more manifold. It is these cases which develop deafmutism, and in them are often seen great discrepancies between the physical and mental symptoms. Many of the endemic cretins show little backwardness in their mental development, although they may have all the physical characteristics of cretins, and on the other hand, some may show cretinous idiocy with but little retardation in growth. In endemic cretins growth is only delayed; even in the most severe cases union of epiphyses takes place.

Although the clinical entities mentioned in the previous paragraph are well recognized, there are many patients who present symptoms of slight thyroid insufficiency, which we are daily overlooking because the symptoms are not so well recognized.

\section{Symptoms of Uncomplicated Slight Thyroid Insufficiency}

The most important symptoms are (1) transitory infiltrations of the skin; (2) hirsute derangements, as partial alopecia, capillary nanism, premature baldness and grayness, absence or premature falling out of the eyebrows; (3) caloric disturbances as coldness of extremities, chilliness, shivering fits, subnormal temperature, chilliness with vasomotor derangement, of which acro-asphyxia, cyanosis, and chilblains are the manifestations; (4) anorexia, tendency to obesity and constipation; (5) fatigue and somnolence; (6) small size of patients and retardation of certain developmental processes (dentition, walking, speech) ; (7) tendency to muscular and articular pains and frontal and occipital headaches, as well as to apathy, indolence and depression, and (8) imperfect development of sexual glands, and diminution of sexual appetite.

Simple inadequacy of the thyroid is rarely observed clinically but is almost invariably associated with symptoms of thyroid excess. The symptoms of slight hyperthyroidism are (1) hypertrichosis and hyperthermia; (2) acro-erythosis with cutaneous humidity; (3) emaciation and diarrhea; (4) restlessness, insomnia ; (5) excessive height, developmental precocity, "syndrome of persistent juvenility"; (6) large, 
brilliant protruding eyes with nystagmiform movements, extreme nervous irritability with cardiac and nervous excitability, and ( 7 ) hyperthyroidic syndromes, as migraine, ophthalmic migraine, asthma, chronic rheumatism, mucous enteritis, urticaria and certain mental symptoms.

\section{Hyperthyroidism}

In 1840 Basedow described three cases of the disease which now bears his name. In 1835 Graves described the same disease, which he believed to be related to hysteria. It was Möbius who in 1886 showed the relationship of Basedow's disease to hyperthyroidism.

Holmgren had shown that Basedow's disease in children leads to accelerated growth and premature union of the epiphyses. Schkarine reported a case of the disease in a $4 \frac{1}{2}$ year old girl who showed abnormally rapid growth. The skeleton of such patients is gracile, and the end phalanges are pointed. In males there is impotence and a loss of libido. In women amenorrhea is an early symptom. In cases in which the disease is of long duration there may be complete atrophy of the entire genital apparatus. Conception in morbus Basedowi is rather infrequent.

Of 3,477 cases only 184 occurred in children under 15 . White Clifford reported a case in an infant: the mother had one previous infant with Basedow's disease. Often a number of members of the same family have it; Oesterreich reports ten cases in one family.

It is now possible to distinguish the symptoms of Graves' disease which might be due to irritation of the sympathetic from those which might be attributed to autonomic stimulation.

\section{BASEDOW SYMPTOMS}

Sympathetico-Tonic

\section{Vagotonic}

1. Pronounced protrusion of the bulb.

2. Von Graefe absent.

3. Loewi's phenomenon positive.

4. Mobius positive.

5. Dry bulbs.

6. Greatly increased activity of heart with less pronounced subjective disturbances.

7. Sweating and diarrhea absent.

8. Falling out of hair.

9. Eosinophilia absent.

10. Inclination to fever.

11. Alimentary glycosuria.

12. Refractory behavior to pilocarpin.

1. Relatively moderate degree of tachycardia.

2. Pronounced subjective heart symptoms.

3. Von Graefe definite.

4. Wide lid clefts.

5. Möbius absent.

6. Slight protrusion of the bulb.

7. Increased lacrimation.

8. Profuse sweating.

9. Diarrhea.

10. Disturbances of digestion.

11. Eosinophilia likely.

12. Alimentary glycosuria absent.

13. No epinephrin glycosuria.

14. Pigmentation.

In 1895 von Mikulicz called attention to the occurrence of enlarged thymus in severe cases of exophthalmic goiter. In 1899 Rehn sug- 
gested that it might be well to attack the thymus gland surgically in this disease. Halstead says "that the thymus plays an important part in Graves' disease has, I think, been demonstrated beyond question by the results which have followed thyroidectomy. That some sort of relation exists between the two organs we have further evidence from the physical examination of the nonfatal cases, from the autopsy table and from experiments on animals." In 40 per cent. of exophthalmic goiter cases the thymus is persistent. Symptoms of Graves' disease which indicate a preponderant influence of the thymus are the vagotonic symptoms. The blood picture in Basedow's is also due to the thymus.

\section{DISTURBANCES OF PARATHYROIDS}

Tetany is the most marked example of insufficient secretion of the parathyroid glands. Tetany occurs in children; it may arise idiopathically in adults, in maternity cases, in certain stomach diseases, in certain infectious diseases and under other conditions. The symptoms of tetany are too well known to need any repetition; only those which have a bearing on other ductless glands will be mentioned here.

In thyroidectomized dogs the glycosuric action of adrenin is diminished; in parathyroidectomized dogs, however, it is increased; in such animals there is also a diminished tolerance for carbohydrates. The trophic disturbances in tetany affect only tissues of ectodermal origin, as hair, nails, skin, gums, and cilliary epithelium; in chronic tetany falling out of hair is common; the nails become brittle; the skin in acute cases assumes a pseudo-edematous appearance. Often pigmentation of skin is observed. Of great interest is the development of cataract in these cases. In chronic insufficiency of parathyroid secretion there is defective development of the teeth and the bones. Some believe that such deficiency in infants leads to rickets, and in adults to osteomalacia. Other diseases which have been attributed to deficient parathyroid secretion are paralysis agitans (Landberg, 1904, Berkley, 1905), myotonia, myoclonia and myoclonic epilepsy. The coincidence of epilepsy and tetany is not infrequent. Redlich collected reports of seventy-two such cases from the literature.

Hyperparathyroidism. - In the few cases of adenoma of the parathyroids reported no signs of hypersecretion were noted. Lundberg and Chvostek believe that hypersecretion of the parathyroids is responsible for myasthemia paralytica. Others believe that myatonia periodica is also due to the same cause.

\section{DISTURBANCES OF THE PINEAL}

There are only about fifty cases reported in the literature: they are mostly due to cysts, gummata or tumors. Pineal disturbances usually affect young individuals. They are usually due to developmental defects, and are far more frequent in the male sex. 
Like the hypophysial tumors, they may give the general symptoms of brain tumors with certain focal signs, and in addition, by interfering with physiologic function, may bring about distinct and characteristic disturbances in nutrition. In enlargements of the pineal, circulatory disturbances develop first, with the formation of varying degrees of hydrocephalus.

The neurologic symptoms are those of increased cerebral pressure, due to the hydrocephalus; they are always present and are among the first noted. Headache is the first symptom and is mostly occipital. Other symptoms are papillary edema, abnormal drowsiness, increased muscular tonus, weakness without paralysis of the extremities and increased reflexes. Pressure on corpora quadrigemina gives rise to ocular and papillary signs, isolated eye palsies and nystagmus. Other symptoms are giddiness and dizziness, staggering gait, asynergia and adiadochokinesis; less constantly excessive thirst, polydipsia with polyuria; glycosuria was observed in a number of cases.

The metabolic symptoms are adiposis, early sexual maturity, and later cachexia. The trophic disturbances are of most interest. There is a rapid and abnormal development of the body and premature development of the genitals. In these cases there is enlargement of the penis, with increase in genital hair and in the general hairiness of the body, increased libido, early masturbation, and in some cases changes of the voice.

Marburg believes that hypopinealism leads to premature develofment of the genitals, hyperpinealism to general adiposity and epinealism to cachexia.

\section{DISTURBANCES OF THE GONADS}

In the gonads (testes-ovary) there are two kinds of tissue, the interstitial tissue and the specific genital gland. The interstitial cells of Leydig in man are of the greatest importance for the development of the primary and secondary characteristics. One of the functions of the male gland may be affected without the other; for instance in abdominal cryptorchism there is no development of secondary male characteristics, but there may be spermatogenesis. In the adult, inguinal cryptorchism leads to no loss of libido. Such men may have ejaculations without spermatozoa; they are potent but sterile. They have the virile habitus; there is beard growth, skeleton is normal. Here the interstitial cells have developed but the genital cells have not. Tandler found in twenty cases of cryptorchism, spermatogenesis not once, and normal interstitial tissue in all. Ancel and Bouin tied the vasa deferentia; after a considerable time spermatogenesis ceased, but the interstitial cells were not affected. Roentgen rays affect the genital cells but not the interstitial cells. 
The female and male bodies resemble each other far more before puberty than later; before puberty they both show the infantile type. In man at time of puberty the larynx enlarges, the voice changes, beard growth becomes prominent; in woman the breasts develop, the pelvis assumes the more feminine type, the form becomes more rounded, there is a deposition of fat around the hips. In both sexes there is a growth of hair on mons veneris and axillae; in woman the hair line is horizontal, whereas in man it is triangular. In man the extremities are longer in proportion to the body length.

\section{HYPOGONADISM}

Eunuchism.-If castration is carried out early, the development of the secondary sexual apparatus remains very much undeveloped (penis, prostate and seminal vesicles remain very small). In older people the penis becomes only a little smaller but the prostate diminishes considerably. There are no erections and no libido; if castration is done late, libido may remain and the subject may have ejaculations of prostatic fluid. The character of such people is entirely changed; the intelligence remains normal. Growth is accelerated and the subject may reach a height of $200 \mathrm{~cm}$.; the union of the epiphyses is delayed, also ossification of sutures of head. The head is small, and the back of the head is flattened; the neck is short; the extremities are long and lower part from umbilicus is longer than above. The pelvis remains infantile; the voice and the larynx remain childish. The bones remain delicate and the muscular markings are fine; the skin is thin and pale and of yellow discoloration. There is adiposity of feminine type, a horizontal fold of tat at the mons veneris, and a deposit of fat on the nates, on the hips, thighs, mammae. The secondary male characteristics are poorly developed. The hair on the head is well developed, no beard growth, no hair on body, in axilla, or on scrotum and perineum.

Castration after puberty in women leads regularly to atrophy of the uterus and vagina; menstruation ceases, the clitoris shrinks and libido diminishes; in a few cases there was increased libido for a time; adiposity generally present.

Eunuchoidism in Adults.-Here we get all the symptoms of eunuchs except the bone changes, as the epiphyses have already united. The penis, testicles, and prostate all become small and atrophy; there is no libido; impotence is present; there is a retrogression of all the male secondary sexual characteristics. In women there is a retrogression of the genitals and adiposity and a loss of pigment, but no loss of hair in axilla or from mons. 


\section{HYPERGONADISM}

Hypergonadism has been noted in children suffering from malignant disease of ovary or testicle. In these cases there is enormous development of the body; the hair on the mons, in the axilla, and on the face begins to grow; hair grows also over the whole body. Libido is developed as in adults. Intelligence is well developed but childish; premature change of voice takes place. Erections and ejaculations have been noted as early as in the first year; in these cases the hyperdevelopment of the genitals precedes the development of the body. There is premature closure of the epiphyses, so that these children are too big for their age, but they cannot become giants; the body shows infantile dimensions.

In females, there is menstruatio praecox; the uterus, vulva and breasts are overdeveloped. There is excessive bodily growth; dentition, changes of teeth, ossification of bone centers, and closure of epiphyses are premature. One of these children was impregnated at 8 years; shortly after this the abnormal growth ceased; she died at the age of 75 years (von Haller).

\section{DISTURBANCES OF THE THYMUS}

Neusser reported a case of tumor of the thymus in a man aged 25 years; the patient was very tall and hypoplasia of the genitals was present. In many cases of myasthenia gravis, hyperplasia of the thymus is found. After operative removal of the gland, even in infancy, hardly any symptoms are observed. But in most of these cases only partial removal was performed so that no definite conclusions can be drawn. Thymus hyperplasia is very often found in Basedow's disease, in acromegaly and in eunuchs.

Katz, in each of sixty-one mentally normal children who died of various diseases, found a normal thymus; in each of twenty-eight mentally feeble children, the thymus was absent. In another series of 292 cases of mentally deficient children the organ was absent in 74 per cent. Lange, Decker, Garri, and Lampè have reported cases of idiocy in which at necropsy the thyroid was found quite normal; the thymus was very small.

Ruhräh and Thompson found atrophy of the thymus in marasmus cases. Thymectomy causes a gradual decrease in the leukocyte count, while an administration of thymus causes an increase of these cells.

In status thymolymphaticus, there may be increased height, gigantism, or dwarfism; the bones may present deformities as in osteitis deformans or acromegaly. The head may be larger or smaller than normal and may present other anomalies; the extremities are long; the epiphyses close late. The facies is pasty and anemic. Adiposity of a 
eunuch type is usually present; the development of male secondary characteristics is deficient; the male form approximates the female configuration. Hair supply is deficient on body, and scrotum; no beard growth; voice is high pitched; pomumadami only slightly developed; penis, testicles and prostate all small ; cryptorchism and aspermatogenesis are often present. This description given by Neusser corresponds very clearly with our present conception of hypogonadism; and as in most of Neusser's cases there was concomitant cryptorchism and aspermatogenesis it is very likely that the symptom complex which he ascribes to status thymolymphaticus may be due to hypogonadism.

In women Neusser noted a deficient hair growth; menstruation delayed or entirely absent; uterus hypoplastic; pelvis small; infantilism of internal genital organs; manly voice; masculine build of larynx and distribution of hair; flat breasts, small hips, hypoplastic heart; congenital mitral stenosis and other congenital heart anomalies, especially congenital narrowing of the aorta and other blood vessels.

\section{DISTURBANCES OF THE PANCREAS}

Bouchardt observed sclerotic changes in the pancreas in cases of diabetes. Mering and Minkowski proved that total extirpation of the pancreas in dogs leads to glycosuria. The opinion was expressed by Laguesse (1893) that the so-called islets of Langerhans may be the seat of the internal secretion of the pancreas. Opie and Weichselbaum proved that in diabetes mellitus the islets are the seat of pathologic lesions.

In the glycosuric stage of diabetes, injections of epinephrin increase the output of sugar, but in the aglycosuric stage no such increase is noted. After thyroidectomy, however, epinephrin glycosuria is diminished, but after parathyroidectomy it is increased.

Claude Bernard could produce glycosuria by puncturing a spot in the fourth ventricle. This glycosuria is produced through the sympathetic system; if the spinal cord above the outlet of the sympathetic is broken no such glycosuria results. Electric stimulation of the splanchnic produces glycosuria. Glycosuria is also found in cerebral hemorrhages, encephalomalacia, tumors of the brain, and especially in tumors of the fourth ventricle.

Hyperglycemia is also produced in extirpation of pancreas, in Bernard's puncture, or puncture of the medulla, stimulation of the splanchnics, and by the introduction of an excess of epinephrin into the blood. An increased sugar tolerance is observed in hypothyroidism, in hypopituitarism and in hypo-adrenalism. In hypogonadism, although there is adiposity, the tolerance for carbohydrates is limited and alimentary glycosuria is more easily evoked. 
In many cases of diabetes there is increased excitability of certain sympathetic nerves, especially of the dilator of the pupil, of the liver, kidney and other organs; but the excitability of the autonomic nerves is not diminished.

In diabetes, impotence is usually found in men, but there is no recession of the secondary sex characteristics. Often there is atrophy of the testicles. In women menstruation is not disturbed but conception is rare. Bramwell and Reutone have described cases of pancreatic infantilism in children.

\section{CLINICAL MANIFESTATIONS OF PLURIGLANDULAR DISTURBANCES}

To the axiom that a man is as old as his arteries may be added that a child is as old as its ductless glands. The ductless glands, like other organs, may prematurely degenerate; at times this is due to inherited insufficiency of the glands, to infection, or to intoxications; the result is a sclerotic atrophy of a number of these glands. Most affected are the thyroid gonads, hypophysis and adrenals. In addition to symptoms of deficient secretion of these glands a terminal cachexia usually develops.

All these cases show symptoms of late hypogonadism. Cachexia and anemia are prominent symptoms; no adiposity occurs, but emaciation with weakness is nearly always present. The face and other parts of body are swollen as in myxedema. Alopecia and loss of hair on the whole body usually take place; pigmentation of skin and mucous membranes is a prominent symptom. Anemia and transient polyuria are at times present. In women degeneration and atrophy of the genital apparatus and of the secondary sexual characteristics is very marked.

In these cases, degeneration of the genitals and retrogression of secondary characteristics is referable to hypogonadism. Alopecia, trophic disturbances of the nails, and teeth, the apathy, headaches and amnesia and myxedematous skin are due to hypothyroidism. The cachexia and the transient polyuria suggest the involvement of the hypophysis. The hypotonia, the severe asthenia and the pigmentation point to the involvement of the adrenals. Spasmophilia and tetanic contractions suggest that the parathyroids may also be involved.

Thompson in a case of marasmus found marked sclerosis of all the ductless glands. Hutchinson, Gilford and Variot and Pironeau* have reported cases of pluriglandular involvement in children. Variot named these cases nanisme type sénile. The cases reported by these

* Since the article was written another case of progeria was reported by C. W. Rand, Boston Med. and Surg. Jour., 1914. 
writers resemble each other as do all cases of cretinism. There is retardation of growth in these cases (may be dwarfed); emaciation with folding of the skin is a prominent symptom. The muscular development is good, but the skeleton remains infantile; the bones are delicate, ends are thickened and the epiphyses close prematurely. The genital development is much retarded; there is deficient hair growth over the whole body, including head and eyebrows, which imparts to these patients a very senile appearance. On necropsy in one of these cases only sclerosis of the pituitary was found. Intelligence in these cases was good. Gilford has named this condition "progeria."

\section{"INTERRELATION OF THE DUCTLESS GLANDS"}

Although our knowledge of the internal secretions is incomplete and confused, much progress has been made in this branch of medical science in the last decade. One fact has been clearly brought out and that is that the physiologic relation of all ductless glands is an intimate one, and that in pathologic conditions of one of them all the other glands are affected. The influence of one gland on another may be compensatory or inhibitory.

The existence of a relationship between the thyroid and the hypophysis is perhaps the most satisfactorily demonstrated of all the possible interrelations of endosecretory organs. The pituitary hypertrophies as a reaction of hypothyroidism. The thyroid exercises normally an inhibition on the pituitary, but stimulates the adrenals; the adrenals inhibit the pancreas, and the pancreas inhibits both the thyroid and the adrenals; the adrenals, however, stimulate the thyroids. In Basedow's disease we have menstrual disorders, amenorrhea, and often atrophy of sex organs; in myxedema we have sex depression, impotence and atrophy of the genitalia. There exists some relationship between these organs, and it is probable that the thyroids have on the sex organs a stimulating effect that is necessary for the normal continuance of their function. In Basedow's disease and in simple congenital goiter, the thymus is often enlarged. In Switzerland the offspring of goitrous mothers often have both thymus and thyroids enlarged. Thyroidectomy raises the assimilation limit for dextrose; therefore the thyroid inhibits the pancreas in its function of promoting glycolysis.

The pituitary has a slightly stimulating effect on the thyroid. These glands are more or less synergic and either can to some extent function vicariously for the other. Cushing found atrophy of the gonads after extirpation of part of the anterior lobe. In acromegaly there is cessation of menstruation, impotence in the male, and atrophy of aplasia of the genitals. The pituitary, therefore, supplies a secre- 
tion that stimulates the sex glands to activity. After prolonged feeding of pituitary there is hyperplasia of the adrenal cortex.

A theory that the adrenals are related to the sex functions was proposed by Meckel as early as 1906 . It was based on the following grounds: 1. In certain aborted fetuses he had noticed that both the adrenals and the gonads were lacking. 2. In animals in which sexuality is marked the adrenals are notably large. 3 . In birds and amphibia the gonads and the adrenals are closely associated in position. 4. He had



Fig. 1.-Chart showing interrelation of endocrine organs. $\longrightarrow$ stimulates;

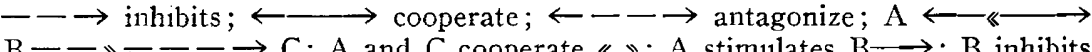
$\mathrm{A} \leftarrow$; $\mathrm{B}$ inhibits $\mathrm{C}-\longrightarrow \rightarrow$; $\mathrm{C}$ has no action on $\mathrm{A}$.

noted adrenal degeneration in several cases of disease of the genitalia. In cases of hermaphroditism marked hypertrophy of the adrenals is sometimes observed. The clinical literature indicates that there is a correlation between the adrenals and the gonads. It further suggests that the adrenals furnish a stimulus to the gonads. In Addison's disease there is hypertrophy of the thymus. The adrenals and the pancreas are mutually antagonistic. In Addison's disease the dextrose limit is high.

Castration causes hypertrophy of the anterior lobe of the pituitary; pregnancy also causes increased activity of the hypophysis. The pituitary is normally held in check by the gonads and when this inhibi- 
tion is removed the pituitary manifests increased activity. The gonads exert a depressing effect on the thymus; the adrenal cortex hypertrophies after castration: the thyroid hypertrophies in menstruation and in pregnancy (Fig. 1).

\section{INFANTILISM}

The term "infantilism," devised by Laségue, means the maintenance of the genital organs in the infantile state of development, with a lack of secondary sex characteristics; there is a failure of the primary and the secondary sex characteristics to appear at the proper time. This may occur in individuals of dwarf growth, of normal growth, and in giants.

Infantilism occurs: (1) in the dwarfing of growth from intoxications as chronic tuberculosis, congenital lues, malaria cachexia, leprosy, pellagra, in severe rickets, chronic alcoholism in childhood, after prolonged and excessive doses of mercury, lead, morphin, tobacco and carbon bisulphid; (2) in all abnormalities of growth which seem to depend on the gross lesions or defects of important internal organs as thyroid, pituitary, gonads, thymus, pancreas, adrenals, kidney, and liver (in fact.all dwarfs except achondroplasiacs present infantilism and puerile habitus) ; (3) in disturbances of growth associated with disturbances of the circulatory system either congenital or beginning very early in life, congenital stenosis of the aorta, stenosis of mitral and aortic valves of the heart, and general defects of the circulatory system; (4) in conditions such as congenital adiposis, progressive muscular dystrophies, microcephaly, spastic diplegia, and ateliosis.

The Brissaud type of infantilism manifests itself mainly by the persistence of the characteristics of childhood, physical and mental, without the evidences of true idiocy and often without true dwarfism. This type of infantilism is probably due to hypothyroidism, and presents the symptoms of myxedema in a mild form.

\section{"DWARFISM"}

Dwarf races seem to have been mentioned in the literature and legends of most languages. Schweinfurth found at the court of King Munza representatives of a dwarfed race to whom he applied the name "Akka." There is among the proletariat of European cities and elsewhere, a great group of very undersized individuals; these are said to be especially common in Bavaria and Italy. Among famous dwarfs may be mentioned Esop, Philetas of Cos, Alypius, Licinius Calvus, Characus, and Carrie Akers, height 2 feet 10 inches, weight 309 pounds.

Growth depends on inherited disposition, nutrition, conditions of life, as surroundings or environment, and habits of life; pathologic 
influences may affect any of these. Dwarfs may be classified into (1) cases which may be possibly caused by either changes of condition or by inherited tendency or both; (2) cases occurring in one or more children, as the defective growth which occurs in lues, in children of drunkards, or those affected by plumbism or other poisons; and also cases of ateliosis or true dwarfism; (3) cases in which influences to growth are brought to bear during intra-uterine life, for instance, dwarf growth of microcephaly or porencephaly; (4) cases in which adverse influences have been exerted during childhood; here, development, at first normal, has after an illness ceased to advance at the usual rate, for instance, in acquired hydrocephalus, chronic meningitis, malaria, cachexia, granular kidney, pneumonitis, congenital heart disease, early acquired heart disease, chronic alcoholism in early childhood; (5) cases due to disorders of the pituitary, thyroid, thymus, adrenals, pancreas and intestine (Herter) ; 6 ) cases occurring in connection with rickets, ateliosis, and achondroplasia.

Dwarf growth may be the result of insufficient development, the premature ossification, and the early union of the epiphyses and diaphysis (achondroplasia). Or it may be due as in true dwarfs (ateliosis) to a persistence of the cartilage disks throughout life. In these cases epiphyses do not join the diaphyses; m unany bones the epiphyses do not appear at all, being represented by cartilage as in the infant; there is no disproportion in the trunk and the extremities. In cretins the cartilage of conjugation persists, ununited with the diaphysis. Eruption of teeth is disturbed in all dwarfs except achondroplasiacs; persistence of milk dentition and delayed eruption of last molars, are common in true dwarfs, in cretins and in microcephalics.

Achondroplasiacs enter the world as such; in true dwarfs the stunting of growth may be congenital or acquired soon after birth or during infancy, or childhood; in these, growth may be retarded to a minimum, or it may be very slowly continuous until quite late in life (thirtieth year). In others growth, having ceased, may recur and slowly continue until still later in life. Few of these reach old age, but many have lived $100,90,80$, or 75 years.

Ateliosis resembles cretinism in facial appearance and in the same peculiar configuration of the skull. Defective development of the genital organs and the puerile habitus are other features common to both. In the true dwarf the deficiency of intelligence occasionally goes as far as idiocy. These two groups seem to merge into one another. And if ateliosis is to be considered a manifestation of dysthyroidism, then achondroplasia must also so be considered, for these two conditions present diametrically opposed symptoms. Myxedema in association with achondroplasia has been recorded more than 
once; sporadic cretinism and achondroplasia may occur in different children of the same family. Dr. Hergothe has also alluded to the existence in the same family of achondroplasia and obesity, rickets and myxedema. Cavazanni records a case of achondroplasia in a child whose mother was afflicted with Graves' disease, and Duranti one of similar association, in which the mother died of liver and renal disease.

The differential points between ateliosis and achondroplasia will be noted from the following:

\section{ACHONDROPLASIA}

Height: Smallness of height, 3 feet 6 inches; 4 feet, 3 feet 2 inches.

Head: Large, round, brachycephalic; frontal and parietal eminences prominent; face small but with large features.

Muscular Development: Excessive; arms are muscular, very short; tips do not touch beyond the great trochanters.

Limbs: The lower limbs are short and massive; show angular deformities above and below the knees. Midpoint may be a quarter of the total height above the symphysis; shortening of limbs is of rhizomelic type. Hands and feet are short, thick, broad fingers of equal length. Main en trident.

Nose: Is flat and broad, retroussé nostrils are large.

Genitals, intelligence, hair, trunk, larynx, skin, dentition normal.

\section{ATELIOSIS}

Height: At 9 years, 19ז/3 inches; at adult age 321/2 inches.

Head: Face and general appearance those of infancy; face is short and broad; head proportionally large, is high, quadrate, prominent eminences; lower jaw and chin are small; head is bracycephalic.

Muscular Development: The musculature proportionate to size; is weak and shows lineaments of childhood.

Limbs: Hands, feet and nails have shape and appearance of childhood; no deformation; the skeleton shows the ridges, grooves and points of musculative origin and insertion; are feebly marked; physical strength is small, though greater than that of children of the same height.

Nose: Bridge depressed; broad; saddle shaped; is short and undeveloped.

Genitals: Secondary sex characteristics wanting; are usually sterile; incomplete descent of testes is usual. There is usually but not always sexual infantilism.

Intelligence: Usually normal; may vary from slightly defective to idiocy.

Hair : No hair on face; neck is short and thick; on the head not abnormal.

Trunk: General bodily proportions are those of normal child; mid part a little above the upper border of symphysis; the proportionate length of the segments of the limbs to one another is also normal.

Larynx: Is small and undeveloped; voice high pitched.

Skin: Not thickened, though it shows wrinkling and bronzing.

Dentition: Delayed.

The Lorain type or dwarfism was described by Lorain (1820). The dwarfism is symmetrical; it nearly always affects males. There are no myxedematous symptoms present, and the genitalia are usually normal; the pubic and axillary hair is wanting. The stature is diminished and slender; the facial appearance, expression, and intelligence are normal. This is not due to hypothyroidism but to anangioplasia, 
that is, a defective development of the arterial system, and to premature ossification. This condition is probably due to an underlying status lymphaticus.

\section{GIGANTISM}

Bollinger includes under giants only those who have attained a height of $205 \mathrm{~cm}$. Brissand and Meige believe that acromegaly and gigantism are one and the same disease; that acromegaly is gigantism in a person in whom the epiphysis had not yet united. Sternberg found that 40 per cent. of all giants have manifestations of acromegaly, and that 20 per cent. of all acromegalics are giants. Gigantism is not infrequently met with in eunuchs and in cases of hypogonadism. Huchard and Launois reported a case in a son of a giant; this boy was of gigantic stature at 12 years; at 18 he was $197 \mathrm{~cm}$; the genitals were normally developed; he lived to 60 years and then developed typical acromegalic manifestations. In the early stages of acromegaly, there is increased sexual potency and libido at times, but usually there is impotence, whereas "the interstitial cells of Leydig" are not affected; or there is hyperfunction of these cells; but in giants without acromegalic symptoms, there are manifestations of deficient secretion of the Leydig cells from the beginning.

\section{ADIPOSITY}

Von Noorden divides adiposity into two classes; one depends on exogenous and the other on endogenous factors. Exogenous adiposity is due to overeating, which often leads to diabetes; the endogenous adiposity is due to disease of ductless glands. Von Noorden showed that glycogen fixation and sugar production may be disturbed, while the fat formation from carbohydrates, may still continue. The fat tissue absorbs the overproduced carbohydrates as fat; there is thus an actual diabetic metabolism disturbance, but without glycosuria; thus we may have a pancreatic adiposity.

Hypothyroidism leads to adiposity; hunger cures in these cases lead to weak heart, but thyroid administration causes great reduction of fat; other signs of hypothyroidism are present. There is much increased tolerance for carbohydrates.

In dystrophia adiposo-genitalis, the fat is distributed in a peculiar way. This really is not an adiposity, for if these patients become emaciated they still preserve the fat pads in their choice places. But at times there is general adiposity in hypophysial cases and then it is due to increased sugar tolerance. These cases do not respond to thyroid, but often do respond to pituitary or testicular extract. The adiposity of pineal disease is probably due to hypophysial involvement.

In adipositas dolorosa, there is a peculiar distribution of the fat; the fat masses are painful, later asthenia and psychical symptoms 
develop. Dercum believes it to be a type of dysthyroidism. In eleven cases which came to necropsy, nine showed changes in the thyroid. Of seven cases in which the hypophysis was examined, five showed pathologic changes.

\section{THE BLOOD}

In all diseases of the thyroid, hypophysis, and adrenals there is a diminution of neutrophils and an increase of the mononuclears, especially the lymphocytes; in half the cases there is leukopenia and in many cases there is eosinophilia. One often finds the same blood picture in status thymolymphaticus, and it is possible that the blood picture in dysendocrinism may be due to an underlying condition of status lymphaticus.

\section{SUMMARY}

In hypogonadism in children, there is increased height; the skeleton is gracile and shows characteristic dimensions (from sole to umbilicus longer than above, wide span and small head). There is characteristic fat deposition and deficient development of secondary sex characteristics. The closure of epiphyses is delayed, as is the ossification of bone centers.

In hypothyroidism there is dwarfism or retardation of growth; the skeleton retains the infantile type; the closure of the epiphyses is much delayed; ossification of bone centers is retarded and the fontanels close late. The ossified bones show slight sclerosis; the bones are plump (in young people with Basedow's disease, there is slight acceleration of growth and premature closure of union). There is retardation of genital development but not to the same extent as in hypogonadism.

Hypopituitarism in children leads to retarded growth; closure of epiphyses and ossification of bone centers is delayed. There is hypoplasia of the genitals, and especially marked non-development of secondary sex characteristics; adiposity of hypogonadism type and skeletal dimensions also resemble those seen in hypogonadism. In young acromegalics, there is premature closure of epiphyses, marked accentuation of secondary characteristics, and premature thickening of the bones with exostoses. In other cases there is retarded development of the genitals with gigantism of type seen in hypogonadism.

In hypergonadism, hyperadrenalism and hyperpinealism, there is premature development of the whole body, accelerated growth with preservation of infantile dimensions, premature development of the genitals, and later, premature closure of the epiphyses; these children are too big for their age, but they can never become giants on account of the closure of the epiphyses.

The closure of the epiphyses and therefore the extent of growth seem to be under the influence of the gonads. The development of 
centers of ossification and the length of the bones seem to be greatly influenced by the thyroid and the hypophysis. In growth retardation due to the thyroid the bones are plump, in that due to the hypophysis they are delicate. In children, however, in Basedow's disease the bones are delicate, and in young acromegalics, they are plump with exostoses.

The anterior lobe of the pituitary and the thyroid control growth; hypersecretion leads to increased growth or gigantism, diminished secretion to diminished growth or dwarfism. Hyposecretion of thymus and pancreas may also lead to diminished growth.

Hyposecretion of the posterior lobe of the pituitary causes adiposity; hypersecretion causes glycosuria and polyuria.

The secondary male sexual characteristics are controlled by the interstitial cells of Leydig and are greatly influenced by the adrenals. The adrenals seem particularly to be related to the growth of a hair on the face and body.

The genital organs are controlled by the interstitial cells, but are secondarily affected by the pituitary, the thyroid, the adrenals, the pineal and the thymus.

Adiposity is present in hyposecretion of posterior lobe of the pituitary, in hypopinealism, in hypogonadism, and in hypothyroidism. It is usually associated with increased tolerance for carbohydrates, except in hypogonadism, in which there is no such increased tolerance. Tendency to glycosuria is present in hypersecretion of posterior lobe of pituitary, in hyperthyroidism, and in hyperadrenalism. Hypothermia is usually associated with adiposity, and hyperthermia with cases in which there is a tendency to glycosuria.

Carbohydrate metabolism is primarily regulated by the pancreas and the adrenals; the pancreas regulates glycogen formation, and the adrenals glycogen fixation; protein metabolism seems to be controlled by the thyroid; the purin bodies by the hypophysis, and the thyroid and calcium excretion seems to be controlled by the parathyroids and the thymus. The hypophysis, the thyroid, and the parathyroids also influence carbohydrate metabolism by their secondary influence on the adrenals and the pancreas. For analysis of the other symptoms see chart.

\section{ILLUSTRATIVE CASES*}

CASE 1.†-Hypopituitarism of both lobes with Basedow's disease (Fig. 2). A. K., 12 years of age. The patient had been complaining of headache, double vision, vertigo and vomiting; he was always cold and suffered a good deal from constipation. Weight 93 pounds, height 53 inches (12 pounds overweight, 4

* Cases 2 to 8 , inclusive, are from the Pediatric Department of Vanderbilt Clinic, service of Dr. C. H. Smith.

† Case 1 has been previously reported in connection with an article on Dyspituitarism, Am. Jour. Dis. Child., September, 1913. 


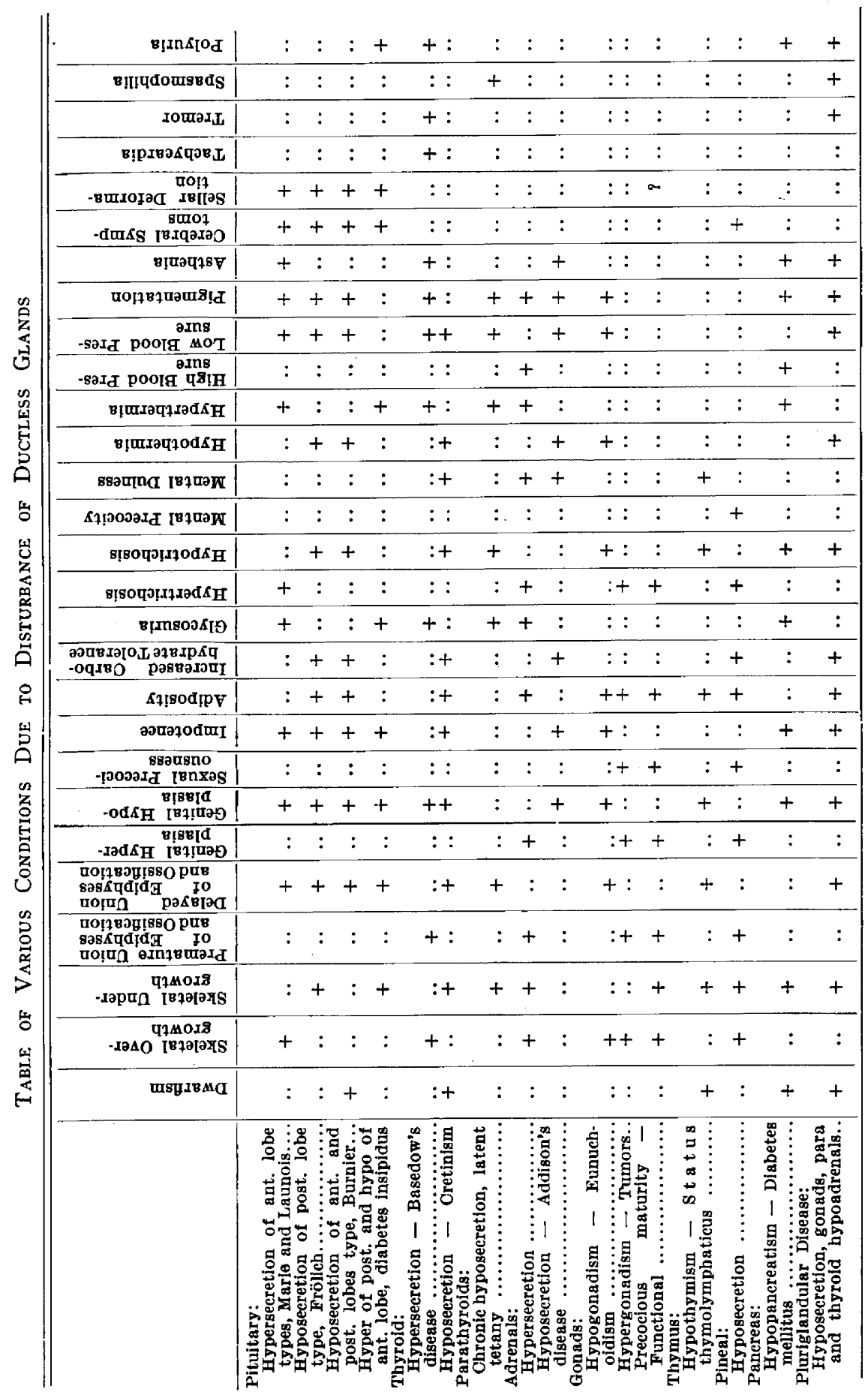


inches under height). Facies was peculiar and expression anxious; slight exophthalmos was present. Adiposity was of a feminine type of distribution; the genitals werc hypoplastic and there was no axillary and no pubic hair. The pulse was 84 to the minute; the temperature subnormal. Bitemporal hemianopsia was present; mentality normal. The sella was enlarged and the centers of ossification were normal: the carbohydrate tolerance was increased to $250 \mathrm{gm}$. The presence of genital hypoplasia, hypotrichosis, adlposis, skeletal under-



Fig. 2

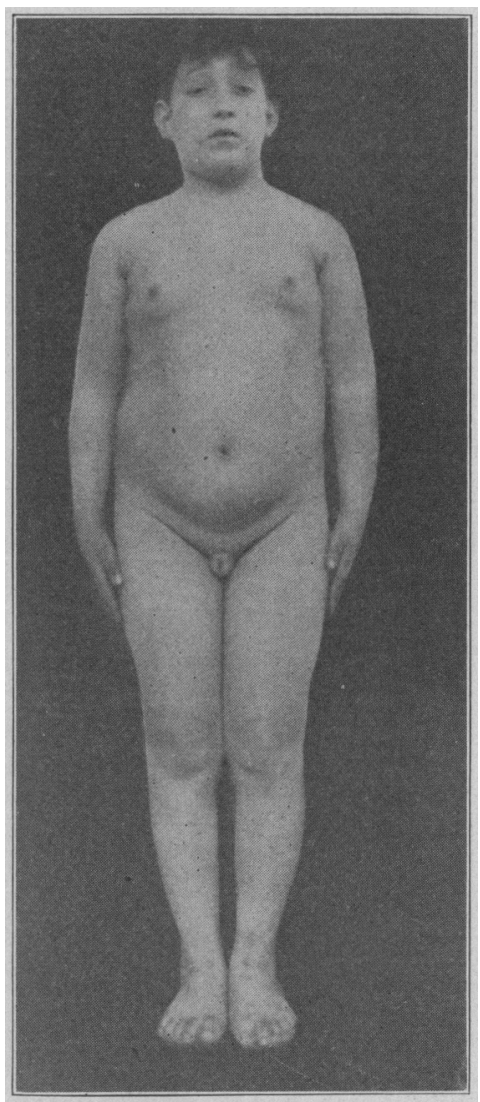

Fig. 3

Fig. 2.-Boy of 12, showing hypopituitarism of both lobes with Basedow's disease (Case 1).

Fig. 3.-Boy of 12 with functional hyposecretion of anterior and posterior lobes of the pituitary (Case 2).

growth with symptoms of cerebral pressure and enlarged sella suggest a tumor of the hypophysis; the presence of exophthalmos tachycardia and tremor suggests the presence of hyperthyroidism which is probably of a compensatory nature. 
Case 2.--Functional hyposecretion of anterior and posterior lobes of the pituitary (Fig. 3). F. P., aged 12, was brought for the rapicl development of adiposity, which is of a feminine type of distribution. The temperature is subnormal. He complained of drowsiness and headache. Fye fundi were normal. Height is 4 feet $71 / 2$ inches; weight 111 pounds. The sella showed slight enlargement; the ossification centers were normal; the carbohydrate tolerance was increased. The adiposity, the hypoplasia of the genitals, the hypotrichosis, the hypothermia and the increased carbohydrate tolerance suggest posterior lobe insufficiency. Absence of cerebral symptoms rules out neoplasm.

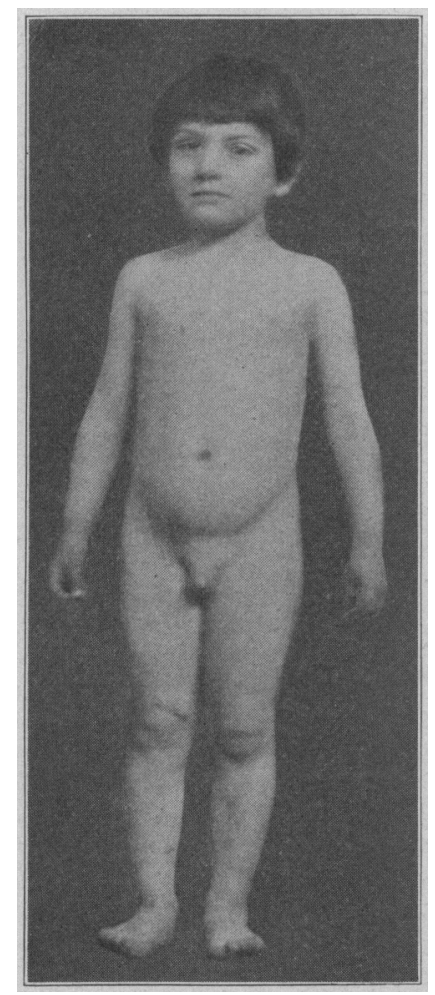

Fig. 4

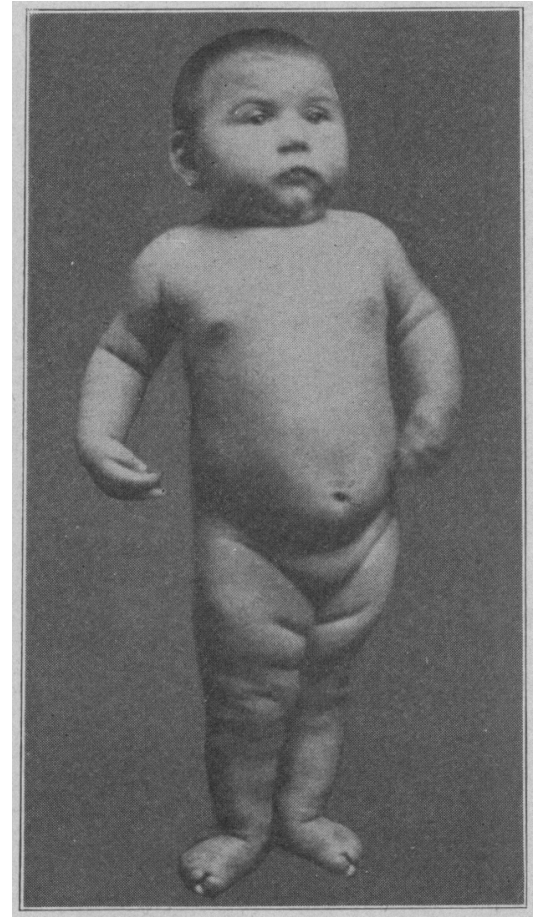

Fig. 5

Fig. 4--Boy of 5 with hyposecretion of anterior lobe and hypersecretion of posterior lobe of the pituitary; diabetes insipidus (Case 3 ).

Fig. 5.-Child of 17 months with hypopinealism (Case 4).

CASE 3.-Hyposecretion of anterior lobe and hypersecretion of posterior lobe of the pituitary; diabetes insipidus (Fig. 4). O. F., aged 5 years. The patient harl been passing a large quantity of urine (120-140 ounces per day) for the last two years; the thirst was very marked. Weight was 32 pounds, height 37 inches; temperature always about $100 \mathrm{~F}$. Genitals were hypoplastic and the testes undescended. The urine showed a specific gravity of 1.007 , no albumin, and had a trace of sugar. Roentgen ray of sella showed a very small pituitary; ossification of wrist centers was delayed; the hands were like those of a cretin. The mentality was normal. The polyuria and the glycosuria suggest hypersecre- 


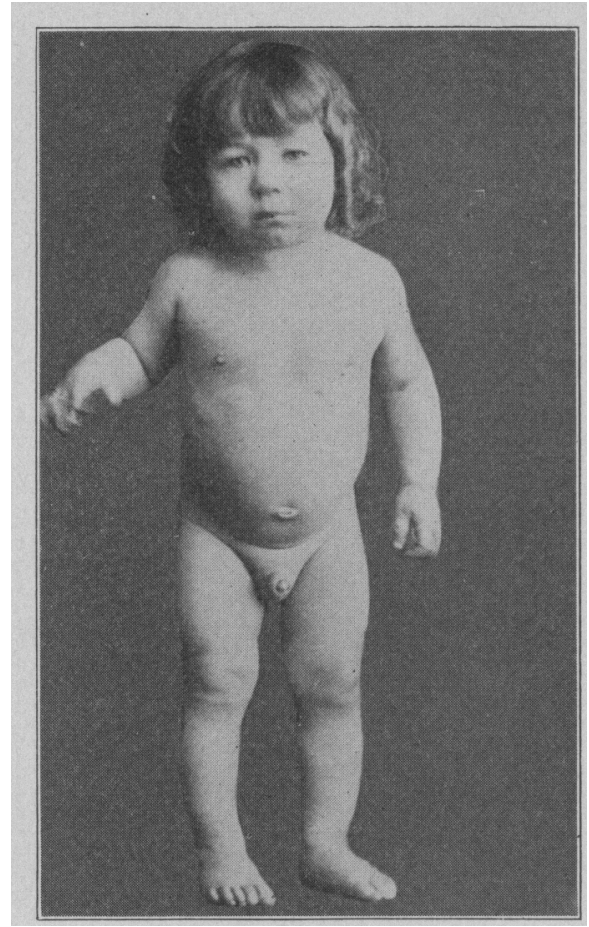

Fig. 6

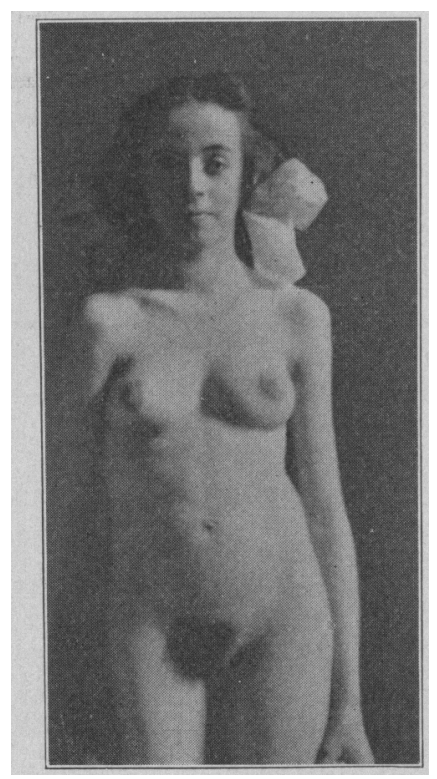

Fig. 8

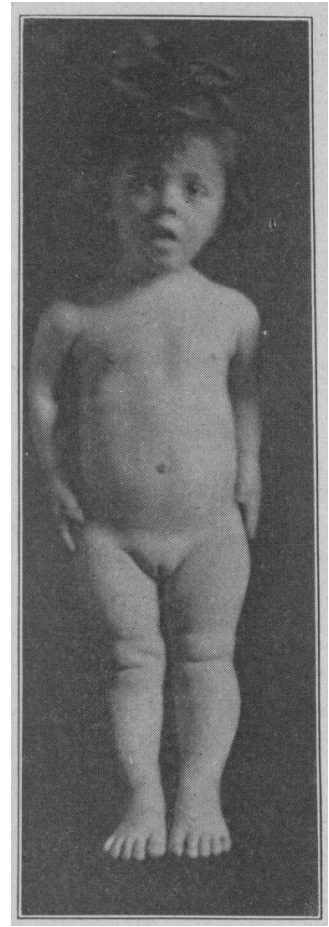

Fig. 7

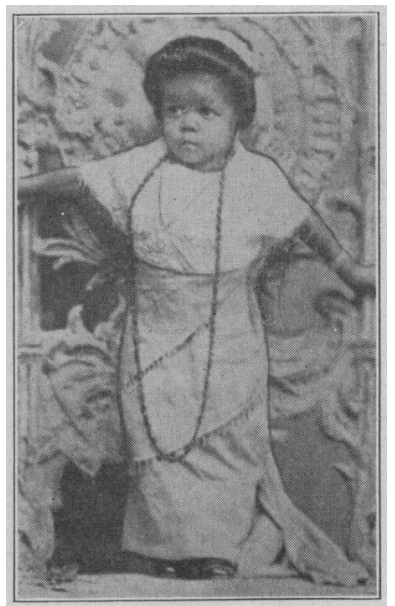

Fig. 9

Iت̈g. 6.-Chile, aged 28 months, with hepothyroidism (Case 5).

Fig. 7.-J. A., achondroplasiac, aged 6 years.

lijg. 8.-A. A., aged 12. Precocions maturity.

Fig. 9.-Case of ateliosis, aged 23. Height 25 inches; weight 12 pounds. 
tion of the posterior lobe; the skeletal undergrowth may possibly be due to hyposecretion of the anterior lobe.

CASE 4.-Hypopinealism. A. B., aged 17 months (Fig. 5). This case presents the following symptoms; adiposity, abnormal development of the breasts, and premature ossification of the head and bone centers of the wrists; circumference of the head only 17 inches; mentality far above that of usual infant of its age; marked spasticity of the legs and exaggerated reflexes. The fundi and the sella are normal. The precocious mental development, the adiposity, the premature ossification and the presence of cerebral symptoms with a normal sella suggest the presence of hypopinealism.

CASE 5.-Hypothyroidism (Fig. 6). I. S., aged 28 months; typical facies and hands of mild cretinism; marked physical and mental backwardness; genitals hypoplastic; temperature subnormal; ossification of bone centers of wrist much delayed; marked improvement under thyroid treatment.

CASE 6.-Achondroplasia (Fig. 7). J. A., aged 6 years.

November, 1911 November, 1912 November, 1914



CaSe 7.-Precocious maturity? Hyperadrenalism? A. A., aged 12 years (Fig. 8), sister of child whose case is reported above. Began to menstruate at 10 years; she had been sent to a sanatorium for pulmonary tuberculosis. She shows abnormal development of the breasts and of the pubic and axillary hair. This is a case of precocious maturity or it may be a case of hyperadrenalism due to tuberculous involvement of the adrenals. The mentality was normal for the age.

CASE 8.-Ateliosis (Fig. 9).-The female (Fig. 9) is 23 years of age and is 25 inches in height; the weight is 12 pounds. Mentality is normal for the age. She presents no deformities; she is a true dwarf.

1967 Seventh Avenue. 